\title{
DESEMPENHO AGRONÔMICO E ATIVIDADE FOTOSSINTÉTICA DE RABANETES NAS CONDIÇÕES AMAZÔNICAS
}

\author{
Antonia Mirian Nogueira de Moura Guerra ${ }^{1 *}$, Júlia Batista Azevedo Ferreira², Thaís Silva Vieira ${ }^{3}$, Jaci \\ Roecker Franco ${ }^{4}$
}

\begin{abstract}
RESUMO - O objetivo deste trabalho foi avaliar o desempenho agronômico de cultivares de rabanete (Raphanus sativus L.) nas condições climáticas amazônicas. Adotou-se o delineamento em blocos ao acaso com quatro tratamentos, sendo as variedades de rabanete: Gigante Siculo, Saxa, Spakler e Zapp, todas da empresa ISLA Sementes ${ }^{\circledR}$. As avaliações foram realizadas aos 15 e 30 dias após a emergência (DAE). Avaliou-se: número de folhas, altura da planta, diâmetro da raiz, massa fresca e seca das folhas e da raiz, produtividade, razão de massa de folhas e raiz, taxa de assimilação líquida de carbono $(A)$, condutância $\left(g_{s}\right)$, taxa transpiratória $(E)$, eficiência instantânea no uso da água $(A / E)$ e relação entre as concentrações interna e externa de carbono $\left(C / C_{a}\right)$. A cultivar Saxa apresentou maior altura de plantas, diâmetro da raiz, massa fresca das folhas e da raiz, enquanto que a cultivar Zapp apresentou maior razão de massa foliar (RMF), e as cultivares Spakler e Saxa mostraram maior razão de massa radicular (RMR) aos 15 DAE. Aos 30 DAE a cultivar Zapp apresentou maior número de folhas, a Gigante Siculo apresentou maior massa fresca das folhas, da raiz e RMR em relação as demais cultivares. Quanto a produtividade, não houve diferença estatística entre as cultivares, entretanto, Saxa, Spakler e Zapp tenderam a maiores produtividades, com 17, 21, 16,12 e 15,23 $\mathrm{t} \mathrm{ha}^{-1}$, respectivamente. No intervalo de 15 dias entre avaliações, todas as cultivares passaram a apresentar o dobro de massa fresca em suas raízes, e as cultivares Gigante Siculo e Saxa apresentaram raízes com 39,78 e 39,92g, com um ganho diário de 1,97 e 1,41g, respectivamente. Zapp e Spakler apresentaram maior taxa fotossintética $(A=19,96$ $\left.\mu \mathrm{mol} \mathrm{CO}_{2} \mathrm{~m}^{-2} \mathrm{~s}^{-1}\right)$ e transpiração $\left(E=5,00 \mathrm{mmol} \mathrm{H}_{2} \mathrm{O} \mathrm{m}^{-2} \mathrm{~s}^{-1}\right)$ em relação as demais, respectivamente. Spakler apresentou maior condutância estomática e relação $C_{i} / C_{a}$ com incrementos de $10,87 \%$ e 5,63\%, respectivamente, em relação à Zapp, bem como menor eficiência instantânea no uso da água frente as demais. Zapp e Saxa foram as cultivares com maior taxa fixação de carbono e eficiência no uso da água a custa de menor transpiração e abertura estomática e maior eficiência da maquinaria fotossintética. Podemos indicar para o cultivo nas condições de Santarém-PA, as cultivares Saxa, Spakler e Zapp, pois apresentaram-se como as mais produtivas.
\end{abstract}

Palavras-chave: partição de assimilados, produtividade, Raphanus sativus L., Santarém- PA.

\section{AGRONOMIC PERFORMANCE AND PHOTOSYNTHETIC ACTIVITY OF RADISHES IN AMAZONIAN CONDITIONS}

\begin{abstract}
The objective of this work was to evaluate the agronomic performance of radish cultivars (Raphanus sativus L.) under the Amazon climatic conditions. A randomized complete block design was used with four treatments: radish: Gigante Siculo, Saxa, Spakler and Zapp, all from the company ISLA Sementes ${ }^{\circledR}$. The spacing adopted was $0.10 \times 0.10 \mathrm{~m}$. The evaluations were performed at 15 and 30 days after the emergency (DAE). The number of leaves, plant height, root diameter, fresh and dry leaf and root mass, yield, leaf and
\end{abstract}

\footnotetext{
${ }^{1}$ Docente do curso de Agronomia da Universidade Federal do Oeste da Bahia, Centro Multidisciplinar Campus de Barra, Av. 23 de Agosto s/nº, Bairro Assunção, CEP: 47100-000, Barra - BA. E-mail: mirianagronoma@hotmail.com.*Autor para correspondência.

${ }^{2}$ Discente do curso de Agronomia da Universidade Federal do Oeste do Pará, Instituto de Biodiversidade e Florestas (Unidade Tapajó), Rua Vera Paz, s/nº, Bairro Salé, CEP:68035-110, Santarém - PA.

${ }_{3}$ Discente do curso de Agronomia da Universidade Federal do Oeste do Pará, Instituto de Biodiversidade e Florestas (Unidade Tapajó), Rua Vera Paz, s/nº, Bairro Salé, CEP:68035-110, Santarém - PA.

${ }^{4}$ Discente do curso de Agronomia da Universidade Federal do Oeste do Pará, Instituto de Biodiversidade e Florestas (Unidade Tapajó), Rua Vera Paz, s/nº, Bairro Salé, CEP:68035-110, Santarém - PA.
} 


\begin{abstract}
root mass ratio, net carbon assimilation rate (A), conductance $\left(g_{s}\right)$, Transpiration rate (E), instantaneous water use efficiency $(\mathrm{A} / \mathrm{E})$, and the relationship between internal and external carbon $\left(\mathrm{C}_{1} / \mathrm{C}_{\alpha}\right)$ concentrations. Saxa cultivar showed higher plant height, root diameter, fresh leaf and root mass, while cultivar Zapp presented higher RMF, and cultivars Spkler and Saxa showed higher RMR at 15 DAE. At 30 DAE, the Zapp cultivar presented the highest number of leaves, Giant Siculo presented a higher fresh leaf mass, root and RMR in relation to the other cultivars. As for productivity, there was no statistical difference between cultivars, however, Saxa, Spakler and Zapp tended to higher yields, with 17.21, 16.12 and 15.23 t ha ${ }^{-1}$, respectively. In the interval of 15 days between evaluations, all cultivars started to show twice the fresh mass in their roots, and the cultivars Gigante Siculo and Saxa showed roots with 39.78 and 39.92g, with a daily gain of 1.97 and $1.41 \mathrm{~g}$, respectively. Zapp and Spakler presented higher photosynthetic rates $\left(A=19.96\right.$ ìmol $\left.\mathrm{CO}_{2} \mathrm{~m}^{-2} \mathrm{~s}^{-1}\right)$ and transpiration ( $E=5.00 \mu \mathrm{mol} \mathrm{H}_{2} \mathrm{O} \mathrm{m}^{-2} \mathrm{~s}^{-1}$ ) relative to the others, respectively. Spakler presented higher stomatal conductance and $\mathrm{Ci} / \mathrm{Ca}$ ratio with increments of $10.87 \%$ and $5.63 \%$, respectively, in relation to Zapp, as well as lower instantaneous efficiency in water use compared to the others. Zapp and Saxa were the cultivars with higher rate of carbon fixation and efficiency in water use at the expense of lower transpiration and stomatal opening and greater efficiency of the photosynthetic machinery. We can indicate the cultivars Saxa, Spakler and Zapp for the cultivation in the conditions of Santarém-PA, because they presented themselves as the most productive.
\end{abstract}

Keywords: partition of assimilates, productivity, Raphanus sativus L., Santarém - PA.

\section{INTRODUÇÃO}

O rabanete (Raphanus sativus L.) pertence à família das Brassicaceaes e é originária da região mediterrânea, possui porte reduzido e tolerância a condições adversas do clima (Filgueira, 2008). Sua raiz consiste de um bulbo comestível de cor vermelha e sabor picante, com propriedades medicinais, expectorante natural e estimulante do sistema digestivo, contendo vitaminas A, B1, B2, potássio, cálcio, fósforo e enxofre (Oliveira et al., 2010). É uma olerícola que tem como característica principal o seu ciclo de produção muito curto.

É uma cultura ainda de pouca expressividade no mercado nacional (Puliti et al., 2009), mesmo assim é explorado em muitas propriedades de pequeno porte dos cinturões verdes das grandes cidades (Oliveira et al., 2010), pois o seu cultivo possibilita um retorno financeiro rápido, com obtenção de renda no período entre duas outras culturas de ciclo mais longo (Matos et al., 2015), além de ser uma opção para a rotação de cultura.

Pode ser usada como cultura "cash" entre outras de ciclo longo, com épocas definidas de plantio, além de ser relativamente rústica e apresentar retorno rápido (Minami et al., 1998). É uma espécie exigente em solo fértil principalmente para evitar distúrbios fisiológicos, como rachadura da raiz e podendo responder a doses de adubo orgânico na faixa de $15 \mathrm{a} 45 \mathrm{t} \mathrm{ha}^{-1}$ de húmus de minhoca ou esterco bovino curtido (Costa et al., 2006).
A região Norte como um todo, e mais especificamente o estado do Pará, carece de muitas informações técnicas sobre a produção de hortaliças, e sobretudo exploração de cultivares adaptadas às condições de produção na região amazônica. O clima quente e úmido favorece a ocorrência de pragas e doenças, que contribuem para a diminuição da produtividade e redução da qualidade da maioria das espécies, tornando-se um desafio de produzir hortaliças nessa região.

Para a introdução de uma cultura em determinado local devemos realizar testes preliminares com a finalidade de avaliar o desempenho agronômico, comportamento produtivo do material genético, as pragas e doenças que poderão afetá-la, bem como ajustar as estratégias de manejo antes de disseminá-lo aos produtores, para assim garantir o bom êxito de sua exploração. O estudo da análise de crescimento é amplamente utilizado para acompanhar o padrão de crescimento da planta ou de partes dela, permitindo inferir a contribuição de diferentes processos fisiológicos para o crescimento vegetal, sendo útil no estudo de variações entre plantas geneticamente diferentes ou sob diferentes condições ambientais (Aguilera et al., 2004).

Considerando as características peculiares que envolvem a exploração agrícola no ecossistema amazônico, devemos sempre que possível adotar o emprego de técnicas agroecológicas de forma a não agridem o meio ambiente e ao mesmo tempo possibilitar aos agricultores a disponibilidade de materiais adaptados a exploração 
nas condições locais. Assim, estudos de comportamento de cultivares nas condições locais são de fundamental importância para uma posterior indicação de sua exploração comercial.

Nesse contexto, a região Norte como um todo, é aquela que apresenta um baixo consumo de hortaliças em função de aspectos culturais, preço elevado, que causa uma dificuldade de acesso por boa parte da população local e também pela dificuldade de produzir, carecendo de muitas informações técnicas sobre a produção de hortaliças. Assim para incentivar o cultivo de rabanete por produtores locais, antes de tudo, faz-se necessário o estudo do comportamento produtivo e adaptativo de algumas cultivares as condições locais para posteriormente, indicar o seu cultivo. Desse modo, este trabalho objetivou avaliar o desempenho produtivo e a atividade fotossintética de cultivares de rabanete nas condições climáticas amazônicas.

\section{MATERIAL E MÉTODOS}

O experimento foi conduzido em área comercial de um horticultor na comunidade rural do Tabocal, município de Santarém - PA (02 ${ }^{\circ} 24^{\prime} 52^{\prime \prime} \mathrm{S} ; 54^{\circ} 42^{\prime}$ '36" $\mathrm{W} ; 152 \mathrm{~m}$ de altitude) na mesorregião do Baixo Amazonas. O cli-ma da região é do tipo Ami, tropical com uma estação anual seca de dois a três meses e precipitação anual média de 2.000 mm (Silva \& Nechet, 2006).

A análise do solo da área experimental $(0-20 \mathrm{~cm})$ apresentou as características apresentadas na Tabela 1.

$\mathrm{O}$ experimento foi disposto em quatro blocos inteiramente casualizado, com quatro repetições, constando de 16 parcelas. As parcelas foram constituídas por quatro cultivares de rabanete (Gigante Siculo, Saxa, Spakler e Zapp, todas da empresa ISLA Sementes $\left.{ }^{\circledR}\right)$. As parcelas apresentaram 1,20 $\mathrm{m}$ de largura por 2,00 $\mathrm{m}$ de comprimento com uma área total de $2,40 \mathrm{~m}^{2}$, sendo que a área útil foi de $1,00 \times 1,80 \mathrm{~m}$, perfazendo 1,80 $\mathrm{m}^{2}$. O espaçamento adotado foi de $0,10 \times 0,10 \mathrm{~m}$ a uma profundidade de semeadura de $2 \mathrm{~cm}$.
O solo foi preparado por meio de uma gradagem e o preparo dos canteiros foi realizado de forma manual. Cada canteiro correspondeu a um bloco, em que cada um possuía dimensão de 1,2 x 10,0 m, altura de aproximadamente $0,25 \mathrm{~m}$ e o espaçamento entre canteiros foi de $0,50 \mathrm{~m}$. Na adubação de plantio foi utilizado o esterco bovino que apresentava a seguinte composição: $\mathrm{N}=10,3 \mathrm{~g} \mathrm{~kg}^{-1} ; \mathrm{P}=11,3 \mathrm{~g} \mathrm{~kg}^{-1} ; \mathrm{K}_{2} \mathrm{O}=1,3 \mathrm{~g} \mathrm{~kg}^{-1} ; \mathrm{Ca}$ $=27,6 \mathrm{~g} \mathrm{~kg}^{-1} ; \mathrm{Mg}=1,5 \mathrm{~g} \mathrm{~kg}^{-1} ; \mathrm{S}=0,8 \mathrm{~g} \mathrm{~kg}^{-1} ; \mathrm{pH}=5,2$; matéria orgânica $(\mathrm{MO})=109,7 \mathrm{~g} \mathrm{~kg}^{-1}$; cinzas $=856,1 \mathrm{~g}$ $\mathrm{kg}^{-1}$. Foi utilizada uma dose de $30 \mathrm{t} \mathrm{ha}^{-1}$ de esterco bovino curtido.

O controle de plantas daninhas foi efetuado através de capina manual e a irrigação foi realizada via microaspersão, visando manter o a umidade do solo próximo à capacidade de campo. Foi realizada uma pulverização com calda de alho e pimenta do reino para controle da mosca branca (Bemisia tabaci) aos 10 dias após a emergência.

As avaliações foram realizadas aos 15 e 30 dias após a emergência (DAE). Foram avaliadas dentre as plantas úteis, dez plantas por repetição com a análise destrutiva das mesmas. Avaliou-se: número de folhas, altura da planta $(\mathrm{cm})$, diâmetro da raiz $(\mathrm{cm})$, massa fresca das folhas $(\mathrm{g})$, massa fresca da raiz $(\mathrm{g})$, massa seca das folhas $(\mathrm{g})$, massa seca da raiz $(\mathrm{g})$ e produtividade $\left(\mathrm{t} \mathrm{ha}^{-1}\right)$. Calculou-se a razão de alocação de biomassa nas folhas e nas raízes através da razão de massa de folhas (RMF - razão entre a massa seca das folhas e a massa seca total) e da raiz (RMR - razão entre a massa seca da raiz e a massa seca total). A massa seca foi obtida pela pesagem após secagem em estufa com circulação de ar a $70^{\circ} \mathrm{C}$ até massa constante, conforme Hunt (1990).

As trocas gasosas foram avaliadas aos 28 dias após a emergência no período compreendido entre as $9 \mathrm{~h}$ e $11 \mathrm{~h}$ da manhã, tomando-se as leituras na folha completamente expandida de cinco plantas por parcela. Para tal, foi utilizado um analisador de gases infravermelhos-IRGA(LC pro+, Analytical Development

Tabela 1 - Características do solo da área experimental na camada de $0-20 \mathrm{~cm}$

\begin{tabular}{|c|c|c|c|c|c|c|c|c|}
\hline $\mathrm{pH}$ em & P (Mehlich 1) & $\mathrm{K}^{+}$ & $\mathrm{Ca}^{2+}$ & $\mathrm{Mg}^{2+}$ & $\mathrm{H}+\mathrm{Al}$ & $\mathrm{S}$ & $\mathrm{V}$ & M.O \\
\hline $\mathrm{H}_{2} \mathrm{O}$ & \multicolumn{2}{|c|}{$\mathrm{mg} \mathrm{dm} \mathrm{m}^{-3}$} & \multicolumn{4}{|c|}{$\mathrm{cmol}_{\mathrm{c}} \mathrm{dm}^{-3}$} & $\%$ & $\mathrm{~g} \mathrm{~kg}^{-1}$ \\
\hline 6,2 & 8,9 & 94 & 4,6 & 1,3 & 1,9 & 6,1 & 76 & 28,7 \\
\hline
\end{tabular}


Company, Hoddesdon, Reino Unido). Durante as avaliações, a umidade relativa do ar foi de aproximadamente $76 \pm 5 \%$, a temperatura foliar variou de 28 a $32{ }^{\circ} \mathrm{C} \mathrm{e}$ a concentração ambiente de $\mathrm{CO}_{2}$ foi cerca de $380 \mu \mathrm{mol}$ mol $^{-1}$ e irradiância de saturação de $1000 \mu$ mol de fótons $\mathrm{m}^{-2} \mathrm{~s}^{-1}$. Foram tomados os parâmetros: taxa de assimilação líquida de carbono $\left(A-\mu \mathrm{mol} \mathrm{CO}_{2} \mathrm{~m}^{-2} \mathrm{~s}^{-1}\right)$; condutância estomática ao vapor de água $\left(g_{\mathrm{s}}-\mathrm{mmol} \mathrm{H}_{2} \mathrm{O} \mathrm{m}^{-2} \mathrm{~s}^{-1}\right)$; taxa transpiratória $\left(E-\mathrm{mmol} \mathrm{H}_{2} \mathrm{O} \mathrm{m}^{-2} \mathrm{~s}^{-1}\right)$; eficiência instantânea no uso da água $\left(A / E\right.$ - $\left(\mu\right.$ mol de $\mathrm{CO}_{2}$ $\left.\mathrm{mmol}^{-1} \mathrm{de}_{2} \mathrm{O}\right)$ e relação entre as concentrações interna e externa de carbono $\left(C_{i} / C_{a}\right)$.

Os resultados obtidos, das características avaliadas, foram submetidos à análise de variância utilizandose o programa estatístico SAEG (Ribeiro Júnior, 2001), sendo os tratamentos comparados entre si pelo teste de Tukey a $5 \%$ de probabilidade.

\section{RESULTADOS E DISCUSSÃO}

Foi constatado aos 15 DAE efeito significativo das cultivares para todas as variáveis avaliadas, exceto o número de folhas, e aos $30 \mathrm{DAE}$ houve mesma tendência de comportamento, exceto para altura de plantas e diâmetro da raiz (Tabela 2).

A cultivar Saxa mostrou-se superior as demais quanto a altura de plantas, diâmetro da raiz, massa fresca das folhas e da raiz, enquanto que a cultivar Zapp apresentou maior RMF, e as cultivares Spakler e Saxa mostraram maior RMR aos 15 DAE (Tabela 2).

Aos 30 DAE constatou-se que a cultivar Zapp apresentou maior número de folhas, enquanto que a Gigante Siculo apresentou maior massa fresca das folhas, da raiz e RMR em relação as demais cultivares. Quanto a produtividade, não houve diferença estatística entre as cultivares, entretanto, Saxa, Spakler e Zapp tenderam a maiores produtividades, com 17,21, 16,12 e 15,23 t ha $^{-1}$, respectivamente (Tabela 2). De acordo com Costa et al. (2006) variações de umidade e temperatura no solo durante o desenvolvimento das plantas podem prejudicar a produtividade e a qualidade das raízes.

As cultivares Gigante Siculo e Zapp lançaram em média, 2 folhas/planta num intervalo de 15 dias, e todas as cultivares avaliadas mostram um incremento médio de $3 \mathrm{~cm}$ no diâmetro da raiz no mesmo intervalo de tempo (Tabela 2). Melo et al. (2014) alcançaram plantas com média de 7,2 folhas que proporcionaram uma produtividade de $13,8 \mathrm{tha}^{-1}$.
Incrementos no número de folhas por planta é um parâmetro de extrema importância, pois estes órgãos são os responsáveis pela produção de fotossimilados que serão exportados e acumulados na raiz, e desse modo, podemos evidenciar uma relação diretamente proporcional entre o aumento no número de folhas e o diâmetro da raiz. Podemos atribuir que as cultivares Gigante Siculo e Zapp apresentaram um melhor aproveitamento da adubação fornecida, uma vez que o esterco bovino apresentava bons níveis de $\mathrm{N}$ e $\mathrm{K}$, vindo a corroborar com o observado por Linhares (2013) em rabanetes com diâmetro máximo de $4,12 \mathrm{~cm}$ planta${ }^{1}$ em condições de adubação verde com jitirana (Merremia aegyptia) incorporada ao solo. Esse comportamento, possivelmente, foi devido a maior disponibilidade de nutrientes que a adubação orgânica forneceu, particularmente $\mathrm{N}$ e $\mathrm{K}$, principais responsáveis pelo aumento e expansão foliar e radicular, levando a maior número de folhas e de diâmetro da raiz.

Em um intervalo de 15 dias entre avaliações, todas as cultivares passaram a apresentar o dobro de massa fresca em suas raízes, sendo que aos $30 \mathrm{DAE}$ as cultivares Gigante Siculo e Saxa apresentaram raízes com 39,78 e $39,92 \mathrm{~g}$, o que gerou um ganho diário de 1,97 e 1,41 $\mathrm{g}$, respectivamente (Tabela 2). Costa et al. (2006) afirmam que a partição da massa seca em rabanete apresenta acúmulo contínuo de massa seca na raiz a partir dos 13 dias após a semeadura (DAS), e em nosso estudo podemos evidenciar estes acúmulos são diferentes entre as cultivares e muito influenciados pelo meio de produção.

Constatou-se até os 15 DAE uma tendência de maior acúmulo de biomassa nas folhas em relação a raiz em todas as cultivares, no entanto, a cultivar Zapp apresentou maior RMF. Já aos 30 DAE, pode-se observar uma inversão no acúmulo de biomassa, sendo que as raízes passaram a ser os detentores de maior quantidade de matéria seca, e a cultivar Gigante Siculo apresentou maior RMR (Tabela 2).

Pedó et al. (2010) verificaram valores inicias para a relação parte aérea/raiz de 2,59 para cultivar Crimson com tendência decrescente ao longo da ontogenia, atingindo $0,89 \mathrm{~g} \mathrm{~g}^{-1}$, assemelhando-se aos obtidos no presente estudo. Este fato está associado a relação fonte/dreno desempenhada pelas folhas e as raízes, onde num primeiro momento o maior acúmulo de biomassa concentrava-se nas folhas que serviam de 
Tabela 2 - Número de folhas, altura de plantas, diâmetro da raiz, massa fresca das folhas e da raiz, razão de massa de folhas (RMF), razão de massa da raiz (RMR) e produtividade avaliados em cultivares de rabanete aos 15 e 30 dias após a emergência (DAE) em Santarém - PA

\begin{tabular}{|c|c|c|c|c|c|}
\hline \multirow{3}{*}{ Variáveis avaliadas } & \multicolumn{5}{|c|}{$15 \mathrm{DAE}$} \\
\hline & \multicolumn{4}{|c|}{ Cultivares } & \multirow[b]{2}{*}{ CV $(\%)$} \\
\hline & Gigante Siculo & Saxa & Spakler & Zapp & \\
\hline Número de folhas por plantans & $5,75^{\mathrm{ns}}$ & $6,10^{\mathrm{ns}}$ & $6,15^{\mathrm{ns}}$ & $6,25^{\mathrm{ns}}$ & 9,1 \\
\hline Altura de plantas $(\mathrm{cm})^{* *}$ & $2,45 b$ & $3,15 \mathrm{a}$ & $2,23 b$ & $2,45 b$ & 9,1 \\
\hline Diâmetro da raiz $(\mathrm{cm}) * *$ & $1,19 b$ & $1,68 \mathrm{a}$ & $1,28 b$ & $1,17 \mathrm{~b}$ & 7,2 \\
\hline Massa fresca das folhas $(\mathrm{g})^{* *}$ & $21,41 \mathrm{a}$ & $21,25 \mathrm{a}$ & $14,63 \mathrm{c}$ & $18,59 b$ & 11,8 \\
\hline Massa fresca da raiz $(\mathrm{g}) * *$ & $10,24 b$ & $18,68 \mathrm{a}$ & $13,03 b$ & $13,04 b$ & 12,3 \\
\hline $\mathrm{RMF}^{* *}$ & $0,64 b$ & $0,58 \mathrm{c}$ & $0,57 \mathrm{c}$ & $0,72 \mathrm{a}$ & 3,13 \\
\hline \multirow[t]{3}{*}{$\mathrm{RMR}^{* *}$} & $0,36 b$ & $0,42 \mathrm{a}$ & $0,43 \mathrm{a}$ & $0,28 \mathrm{c}$ & 5,33 \\
\hline & \multicolumn{5}{|c|}{$30 \mathrm{DAE}$} \\
\hline & Gigante Siculo & Saxa & Spakler & Zapp & $\mathrm{CV}(\%)$ \\
\hline Número de folhas por planta ${ }^{* *}$ & $7,35 b$ & $7,83 \mathrm{ab}$ & $7,45 \mathrm{ab}$ & $8,65 \mathrm{a}$ & 7,2 \\
\hline Altura de plantas $(\mathrm{cm})^{\mathrm{ns}}$ & $25,88 \mathrm{a}$ & $25,20 \mathrm{a}$ & $22,75 \mathrm{a}$ & $25,40 \mathrm{a}$ & 10,7 \\
\hline Diâmetro da raiz $(\mathrm{cm})^{\mathrm{ns}}$ & $4,86 \mathrm{a}$ & $4,90 \mathrm{a}$ & $4,83 \mathrm{a}$ & $4,76 \mathrm{a}$ & 3,94 \\
\hline Massa fresca das folhas $(\mathrm{g})^{*}$ & $26,07 a$ & $23,28 \mathrm{ab}$ & $21,61 b$ & $24,48 \mathrm{ab}$ & 7,4 \\
\hline Massa fresca da raiz $(\mathrm{g})^{* *}$ & $39,78 \mathrm{a}$ & $39,92 \mathrm{a}$ & $30,57 b$ & $32,61 b$ & 3,3 \\
\hline $\mathrm{RMF}^{*}$ & $0,22 b$ & $0,32 \mathrm{ab}$ & $0,42 \mathrm{a}$ & $0,34 \mathrm{ab}$ & 12,2 \\
\hline RMR* & $0,78 \mathrm{a}$ & $0,68 \mathrm{ab}$ & $0,58 b$ & $0,66 \mathrm{ab}$ & 11,3 \\
\hline Produtividade $\left(\mathrm{t} \mathrm{ha}^{-1}\right)^{* *}$ & $11,75 b$ & $17,21 \mathrm{a}$ & $16,12 \mathrm{a}$ & $15,23 \mathrm{a}$ & 7,7 \\
\hline
\end{tabular}

Médias seguidas pela mesma letra minúscula na linha não diferem entre si pelo teste de Tukey a 5\% de probabilidade. CV: coeficiente de variação. ${ }^{\text {ns }}$,** ou *: não significativo, significativo a $1 \%$ ou $5 \%$ de probabilidade pelo teste $F$, respectivamente.

órgãos fotossintetizantes para a produção de fotossimilados que seriam posteriormente exportados e acumulados nas raízes, bem como, neste momento aquelas ainda estavam em fase de formação. Isso demonstra a força de dreno desenvolvida pelas raízes de modo que é favorecido um incremento de massa em um curto intervalo de tempo. Pedó et al. (2011) estudando a partição de assimilados e atributos morfológicos em três cultivares de rabanete observaram quantidade de matéria seca de raiz baixa até os 19 dias após a semeadura, no entanto próximo ao final do ciclo da cultura a produção de fitomassa seca aumentou de forma acentuada estudando a mesma cultivar do presente experimento. Estes resultados também foram similares aos obtidos por Costa et al. (2006) ao avaliar o crescimento do rabanete.

As cultivares avaliadas neste trabalho não apresentaram diferenças significativas para a taxa fotossintética $(A)$ e a transpiração $(E)$, porém Zapp $\left(A=19,96\right.$ ìmol $\left.C_{2} \mathrm{~m}^{-2} \mathrm{~s}^{-1}\right)$ e Spakler $(E=5,00 \mathrm{mmol}$ $\left.\mathrm{H}_{2} \mathrm{Om}^{-2} \mathrm{~s}^{-1}\right)$ tenderam a se destacar em relação as demais, respectivamente (Tabela 3 ).
A cultivar Spakler apresentou maior condutância estomática $\left(g_{s}\right)$ e relação $C_{i} / C_{a}$ com incrementos de $10,87 \%$ e 5,63\%, respectivamente, em relação à Zapp. Por outro lado, a Spakler foi a única cultivar que apresentou menor eficiência instantânea no uso da água $(A / E)$ frente as demais (Tabela 3). Assim, essa cultivar tendeu a ser menos eficiente no uso de água em relação as demais, pois a manutenção do maior influxo interno de $\mathrm{CO}_{2}$ foi as expensas de maior quantidade de água.

Os dados do presente estudo corroboram parcialmente com os observados por Santos et al. (2010) que verificam que aumentos da $g_{s}$ levaram ao aumento do $C_{i}$, aumentando, consequentemente a fotossíntese, porém constatamos redução na fotossíntese, e que a maior fotossíntese ocorreu na cultivar Zapp em condições de menor $g_{s}$, e $C_{i} / C_{a}$.

Alterações na taxa fotossintética podem ser ocasionadas por limitações estomáticas com mudanças na abertura dos estômatos e resistência ao influxo de $\mathrm{CO}_{2}$, ou limitações nas reações bioquímicas e inibição da atividade da rubisco, desse modo, através da relação $C_{i} / C_{a}$ podemos constatar a eficiência ou ineficiência 
Tabela 3 - Taxa assimilatória líquida de carbono $(A)$, transpiração $(E)$, condutância estomática $\left(g_{s}\right)$, eficiência instantânea no uso da água $(A / E)$ e relação entre as concentrações interna e externa de carbono $\left(C_{i} / C_{a}\right)$ de cultivares rabanetes aos 28 dias após a emergência em Santarém - PA

\begin{tabular}{|c|c|c|c|c|c|}
\hline Cultivares & $\begin{array}{c}\text { A (ìmol } \\
\left.\mathrm{CO}_{2} \mathrm{~m}^{-2} \mathrm{~s}^{-1}\right)^{\mathrm{ns}}\end{array}$ & $\begin{array}{c}E(\mathrm{mmol} \\
\left.\mathrm{H}_{2} \mathrm{O} \mathrm{m}^{-2} \mathrm{~s}^{-1}\right)^{\mathrm{ns}}\end{array}$ & $\begin{array}{c}g_{\mathrm{s}}(\mathrm{mmol} \\
\left.\mathrm{H}_{2} \mathrm{O} \mathrm{m} \mathrm{m}^{-2} \mathrm{~s}^{-1}\right)^{* * *}\end{array}$ & $\begin{array}{l}A / E\left(\mu \mathrm{mol} \mathrm{CO}_{2}\right. \\
\left.\mathrm{mmol} \mathrm{H}_{2} \mathrm{O}^{-1}\right)^{* * *}\end{array}$ & $C_{i} / C_{a}^{* *}$ \\
\hline Zapp & $19,96^{\mathrm{a}}$ & $4,81^{\mathrm{a}}$ & $491,67^{c}$ & $4,16^{\mathrm{a}}$ & $0,67^{\mathrm{b}}$ \\
\hline Gigante Siculo & $19,26^{\mathrm{a}}$ & $4,90^{\mathrm{a}}$ & $526,67^{b}$ & $3,90^{\mathrm{a}}$ & $0,69^{a b}$ \\
\hline Spakler & $19,20^{\mathrm{a}}$ & $5,00^{\mathrm{a}}$ & $551,66^{\mathrm{a}}$ & $3,80^{\mathrm{b}}$ & $0,71^{\mathrm{a}}$ \\
\hline Saxa & $19,36^{\mathrm{a}}$ & $4,85^{\mathrm{a}}$ & $499,16^{\mathrm{c}}$ & $4,00^{\mathrm{a}}$ & $0,68^{b}$ \\
\hline CV (\%) & 4,9 & 9,2 & 8,7 & 2,5 & 2,8 \\
\hline
\end{tabular}

Médias seguidas pela mesma letra minúscula na linha não diferem entre si pelo teste de Tukey a 5\% de probabilidade. CV: coeficiente de variação. ns ${ }^{* *}$ ou *: não significativo, significativo a $1 \%$ ou $5 \%$ de probabilidade pelo teste $F$, respectivamente.

nas reações de fixação de carbono, sendo que quanto mais se aproximar de 1 essa razão, menos eficiente é esse processo, em razão de problemas na maquinaria fotossintética. Dessa forma podemos inferir que as condições de cultivos de Santarém - PA, levaram a cultivar Spakler a apresentar uma menor eficiência na fixação de carbono.

Edmond et al. (1967) observaram que em uma cultura, quando conduzida dentro de variação ótima de luminosidade com outros fatores favoráveis, a fotossíntese é elevada e a quantidade de carboidratos utilizados para o crescimento e desenvolvimento da planta é alta. Em estudos realizados em couve chinesa, Brassica oleracea (Issarakraisila et al., 2007) e orégano (Origanum vulgare L.) (Marques et al., 2009) verificaram correlação positiva entre a fotossíntese e a transpiração em plantas desenvolvidas em ambiente protegidos. Outros estudos constataram que em diferentes espécies cultivadas em ambiente protegido, com concentração de $\mathrm{CO}_{2}$ elevada, ocorreu aumento instantâneo da eficiência do uso da água, relacionados com a diminuição da condutância e transpiração (Canizares et al., 2004; Erismann et al., 2006).

Podemos afirmar que Zapp e Saxa foram as cultivares fotossinteticamente mais eficiente, pois apresentaram maior taxa de fixação de carbono e eficiência no uso da água a custa de menor transpiração e abertura estomática, refletindo em maior eficiência da maquinaria fotossintética garantindo maiores produtividades. Isso nos leva a acreditar que houve uma maior eficiência na partição e acúmulo dos fotossimilados nas raízes.

Os incrementos observados nos componentes de produtividade e nos parâmetros de trocas gasosas se devem a interação entre a cultivar e o ambiente, onde cada material genético demonstrou o seu comportamento frente as condições ambientais que puderam proporcionar maior condutância estomática, influxo de $\mathrm{CO}_{2}$, fotossíntese e por fim, produção e acúmulo de biomassa.

\section{CONCLUSÕES}

As cultivares Gigante Siculo e Saxa apresentaram as maiores raízes em diâmetro e peso, com 39,78 e 39,92g, 4,86 e $4,90 \mathrm{~cm}$, o que gerou um ganho diário de 1,97 e $1,41 \mathrm{~g}$, respectivamente.

A cultivar Zapp apresentou maior número de folhas aos 30 DAE.

Gigante Siculo apresentou maior massa fresca das folhas, da raiz e RMR em relação as demais cultivares aos 30 DAE.

Zapp e Saxa foram as cultivares com maior taxa de fixação de carbono e eficiência no uso da água a custa de menor transpiração e abertura estomática e maior eficiência da maquinaria fotossintética.

Podemos indicar para o cultivo nas condições de Santarém - PA, as cultivares Saxa, Spakler e Zapp, pois apresentaram-se como as mais produtivas.

\section{AGRADECIMENTOS}

Ao CNPq pela concessão da bolsa IC ao segundo autor; à Canto Verde Hortaliças pela área para condução do experimento.

\section{LITERATURA CITADA}

AGUILERA, D.B.; FERREIRA, F.A.; CECON, P.R. Crescimento de Siegesbeckia orientalis sob diferentes condições de luminosidade. Planta daninha, v.22, p.43-51, 2004. 
CANIZARES, K.A.L.; RODRIGUES, J.D.; GOTO, R. Crescimento e índices de troca gasosa em plantas de pepino irrigadas com água enriquecida com $\mathrm{CO}_{2}$. Horticultura Brasileira, n.22, v.4, p.706-711, 2004.

COSTA C.C.; OLIVEIRA C.D.; SILVA C.J.; TIMOSSI, P.C.; LEITE I.C. Crescimento, produtividade e qualidade de raízes de rabanete cultivadas sob diferentes fontes e doses de adubos orgânicos. Horticultura

Brasileira, v.24, p.118-122, 2006.

EDMOND, J.B.; SENN, T.L.; ANDREWS, E.S. Princípios de horticultura. México: Continental, 1967. p.119-134.

ERISMANN, N.M.; MACHADO, E.C.; GODOY, I.J. Capacidade fotossintética de genótipos de amendoim em ambiente natural e controlado. Pesquisa Agropecuária Brasileira, v.41, n.7, p.1099-1108, 2006.

FILGUEIRA, F.A.R. Novo manual de olericultura: agrotecnologia moderna na produção e comercialização de hortaliças. Viçosa, UFV, 2008. 421p.

HUNT, R. Basic growth analysis. London: Unuin Hyman, Academic Division of Unwin Hyman Ltd, 1990. 112p. http://dx.doi. org/10.1007/97894-010-9117-6

ISSARAKRAISILA, M.; MA, Q.; TURNER, D.W. Photosynthetic and growth responses of juvenile Chinese kale (Brassica oleracea var. alboglabra) and Caisin (Brassica rapa subsp. parachinensis) to waterlogging and water deficit. Scientia Horticulturae, v.111, p.107-113, 2007.

LINHARES, P.C.F. Adubação verde como condicionadora do solo. Revista Campo e Negócios, v.11, n.127, p.22-23, 2013.

MARQUES, P.A.A.; BERNARDI FILHO, L.; SANTOS, A.C.P. Crescimento, produção de óleo essencial e trocas gasosas em orégano influenciados por diferentes lâminas de irrigação. Ciência Rural, v.39, n.6, p.18881892, 2009.
MATOS, R.M.; SILVA, P.F.; LIMA, S.C. et al. Partição de assimilados em plantas de rabanete em função da qualidade da água de irrigação. Journal of Agronomic Sciences, v.4, n.1, p.151-164, 2015.

MELO, F.N.B.; LINHARES, P.C.F.; SILVA, E.B.R.; NEGREIROS, A.M.P.; DANTAS NETO, J.B.

Desempenho produtivo do rabanete sob diferentes quantidades de palha de carnaúba mais esterco bovino em cobertura.

Agropecuária Científica no SemiÁrido, v.10, n.3, p.47-52, 2014.

MINAMI, K.; CARDOSO, A.I.I.; COSTA, F.; DUARTE, R. Efeito do espaçamento sobre a produção em rabanete. Bragantia, v.57, p.169173, 1998.

OLIVEIRA, F.R.A. Interação entre salinidade e fósforo na cultura do rabanete. Revista

Ciência Agronômica, v.41, n.4, p.519-526, 2010.

PEDÓ, T.; LOPES, N.F.; AUMONDE, T.Z.; MORAES, D.M. Partição de assimilados e atributos morfológicos em três cultivares de rabanete. Tecnologia \& Ciência Agropecuária, v.5, n.2, p.23-28, 2011.

PEDÓ, T.; LOPES, N.F.; MORAES, D.M.; AUMONDE, T.Z.; SACCARO, E.L. Crescimento de três cultivares de rabanete (Raphanus sativus) ao longo da ontogenia das plantas.

Tecnologia \& Ciência Agropecuária, v.4, n.3, p.17-21, 2010.

PULITI, J.P.M.; REIS, H.B.; PAULINO, H.D.M. et al. Comportamento da cultura do rabanete em função de fontes e doses de cálcio.

Horticultura Brasileira, Brasília, v.27, p.3003-3008, 2009.

RIBEIRO, A.C.; GUIMARÃES, P.T.G.; ALVAREZ, V.H. Recomendações para o uso de corretivos e fertilizantes em Minas Gerais: $5^{\text {a }}$ aproximação. Viçosa:

Comissão de fertilidade do solo do estado de Minas Gerais, 1999. 359p. 
RIBEIRO JÚNIOR, I.R. Análises estatísticas no SAEG. Viçosa: UFV, 2001. 301p.

SANTOS, C.M.; GONÇALVES, E.R.; ENDRES, L.; GOMES, T.C.A.; JADOSKI, C.J.; NASCIMENTO, L.A.; SANTOS, E.D. Atividade fotossintética em alface (Lactuca sativa L.) submetidas a diferentes compostagens de resíduos agroindustriais. Pesquisa Aplicada \& Agrotecnologia, v.3, n.3, p.103-112, 2010.
SILVA, A.R.; NECHET, D. Características climáticas de alguns municípios produtores de soja do estado do Pará. In: CONGRESSO BRASILEIRO DE METEOROLOGIA, 14.

Anais... Florianóplois-SC, 2006. Disponível em: http://www.cbmet.com/ edicoes.php?pageNum_Recordset busca $=4 \&$ totalRows_Recordset busca $=1006 \&$ cgid $=14$. Ácesso em: 10 de Setembro de 2012.

Recebido para publicação em 27/6/2017 e aprovado em 06/9/2017 